\title{
HUBUNGAN KADAR HEMOGLOBIN IBU HAMIL DENGAN BERAT BAYI LAHIR
}

\author{
Ni Made Egar Adhiestiani \\ STIKES Bina Usada Bali \\ e-mail: adhiestiani@gmail.com
}

\begin{abstract}
Weight is an indicator of a newborn baby. Lower and excess newborn weight has higher risk of getting problems. The cause is nutritional problems; one of them is nutritional experienced by pregnant women with the lower hemoglobin level in the blood. The research was conducted at Independence Midwifery Practice of Dr. Putu Mastiningsih, S.ST., M.Biomed in Blahkiuh, Abiansemal, Badung, Bali. This research was descriptive analytical research with cross sectional design to investigate the correlation between maternal hemoglobin level and newborn weight. The subject of this research was maternal mother who did regular examination until having labor in 2019. The collected data were maternal hemoglobin level and newborn weight. The result of this research showed the characteristics of the respondents based on age, education, and occupation in 2019 was 97 respondents (78.9\%) were in the age of 20 - 35 years old, 56 respondents (45.4.\%) had middle-level of education, and 78 respondents (63.4\%) were working. The bivariate analysis showed that there was a correlation between hemoglobin level and newborn weight by using Chi-square test and obtained $p(0.000)<\alpha$ (0.05).
\end{abstract}

Keywords: newborn weight, hemoglobin level,pregnancy

\begin{abstract}
ABSTRAK
Berat badan merupakan salah satu indikator kesehatan bayi baru lahir. Berat bayi lahir rendah dan berlebih, lebih besar resikonya mendapatkan masalah. Penyebabnya adalah permasalahan gizi salah satunya yaitu anemia gizi pada ibu hamil dimana kadar hemoglobin dalam darah tergolong rendah. Penelitian ini dilakukan di PMB Dr. Putu Mastiningsih, S.ST., M.Biomed di Blahkiuh, Abiansemal, Badung, Bali. Jenis penelitian yang digunakan adalah deskriptif analitik dengan menggunakan pendekatan cross sectional untuk mengetahui hubungan antara kadar hemoglobin ibu hamil dengan berat bayi lahir. Subyek penelitian ini adalah ibu hamil yang melakukan pemeriksaan kehamilan secara rutin kemudian bersalin pada tahun 2019. Data yang dikumpulkan adalah data sekunder yaitu kadar hemoglobin ibu hamil dan berat bayi lahir yang diperoleh dari buku register. Hasil penelitian menunjukan karakteristik responden berdasarkan usia, pendidikan, dan pekerjaan ibu pada Tahun 2019 adalah 97 responden (78,9\%) berusia 20 - 35 tahun, 56 responden (45,5\%) mempunyai pendidikan menengah, dan 78 responden $(63,4 \%)$ bekerja. Hasil analisis bivariat menunjukan adanya hubungan antara kadar hemoglobin dengan berat bayi lahir uji Chi Kuadrat menunjukan bahwa p $(0,000)<\alpha(0,05)$.

Kata kunci: berat bayi lahir, kadar hemoglobin, kehamilan
\end{abstract}

\section{PENDAHULUAN}

UNICEF (United Nations Children's Fund) melaporkan pada tahun 2018, setiap tahunnya satu juta bayi di seluruh dunia meninggal saat lahir. Hasil Survei Demografi dan Kesehatan Indonesia (SDKI) menunjukkan dari tahun ke tahun AKB (Angka Kematian Bayi) mengalami penurunan signifikan. Dari 68 kematian per 1.000 kelahiran hidup pada 1991, hingga 24 kematian per 1.000 kelahiran hidup pada tahun 2017. AKB di Indonesia terus menurun setiap tahun. Namun, jalan memerangi AKB masih panjang karena Indonesia masih merupakan 1 dari 10 negara yang jadi fokus kampanye Every Child Alive 2018 UNICEF (Kementrian Kesehatan RI, 2017).

Menurut Profil Kesehatan Bali, AKB tahun 2017 sebesar 4,8 per 1.000 kelahiran hidup. AKB di Provinsi Bali dari tahun 2013 sampai dengan tahun
2017 menunjukan trend yang fluktuatif, meski sudah lebih rendah dari angka kematian bayi secara nasional, tapi masih perlu mendapat perhatian kita bersama. Permasalahan yang berkaitan dengan kematian bayi di Provinsi Bali antara lain adalah penyebab kematian masih didominasi oleh karena BBLR dan asfiksia, masih adanya disparitas angka kematian bayi antar kabupaten/kota. Persentase bayi dengan berat badan lahir rendah (BBLR) di Provinsi Bali sebesar 2,6\% (Dinas Kesehatan Provinsi Bali, 2017).

Faktor-faktor yang mempengaruhi berat bayi lahir b, yaitu: Faktor ibu, umur, paritas, ras, infertilitas, riwayat kehamilan tidak baik, lahir abnormal, jarak kelahiran terlalu dekat, BBLR pada anak sebelumnya, penyakit akut dan kronik, kebiasaan tidak baik seperti merokok dan minum alkohol, preeklamsi, faktor plasenta, tumor dan kehamilan 
ganda dan faktor janin infeksi bawaan dan kelainan kromosom13. Laporan-laporan dari seluruh dunia menyebutkan bahwa frekuensi anemia dalam kehamilan cukup tinggi, terutama di negara-negara berkembang, yaitu 10-20\%. Frekuensi anemia dalam kehamilan di Indonesia menurut Hoo Swie Tjiong (1962) adalah 18,5\% dan menurut Njong Tiong Tiat dan Poerwo Soedarmo (1975) adalah $16,1 \%$ pada triwulan pertama dan $49,9 \%$ pada triwulan ketiga (Mochtar, 2012).

Berdasarkan studi pendahuluan yang dilakukan di PMB Dr. Putu Mastiningsih, S.ST., M.Biomed di Blahkiuh, Abiansemal, Badung, Bali pada tanggal 23 Mei tahun 2019 dengan melihat rekam medis ibu hamil dan ibu bersalin tahun 2018, peneliti mengambil 10 data ibu bersalin diperoleh $4 \mathrm{ibu}$ bersalin dengan berat bayi lahir kurang dari 2500 gram (BBLR) dan 6 ibu bersalin dengan berat bayi lahir 2500 - 4000 gram (BBLN). Dari 4 ibu bersalin dengan berat bayi lahir kurang dari 2500 gram, 3 diantaranya memiliki kadar $\mathrm{Hb}<11 \mathrm{gr} / \mathrm{dl}$ dan $1 \mathrm{ibu}$ bersalin memiliki kadar $\mathrm{Hb}>11 \mathrm{gr} / \mathrm{dl}$. Sedangkan dari 6 ibu bersalin dengan berat bayi lahir $2500-$ 4000 gram, 2 diantaranya memiliki kadar $\mathrm{Hb}<11$ gr/dl dan 4 ibu bersalin memiliki kadar $\mathrm{Hb}>11 \mathrm{gr} / \mathrm{dl}$. Oleh karena itu penulisingin mengetahui hubungan antara kadar hemoglobin dengan berat bayi lahir

Tujuan umum penelitian ini adalah untuk mengetahui hubungan antara kadar hemoglobin ibu hamil dengan berat badan bayi lahir di PMB Dr. Putu Mastiningsih, S.ST., M.Biomed di Blahkiuh, Abiansemal, Badung, Bali. Sedangkan tujuan khususnya terbagi menjadi tiga yaitu untuk mengetahui mengetahui karakteristik responden meliputi usia, pendidikan, dan pekerjaan ibu hamil, untuk mengetahui kadar hemoglobin ibu hamil dan untuk mengetahui berat bayi lahir.

\section{METODE}

Jenis penelitian yang digunakan adalah deskriptif analitik dengan menggunakan pendekatan cross sectional. Data dalam penelitian ini diperoleh dari catatan rekam medik ibu hamil yang melakukan pemeriksaan kehamilan pada trimester tiga yaitu usia kehamilan 20 - 40 minggu khususnya pemeriksaan kadar hemoglobin dan data berat bayi lahir pada rekam medik dikumpulkan bersamaan. Waktu penelitian pada bulan Januari 2020. Sampel dalam penelitian ini adalah ibu bersalin di PMB Dr. Putu Mastiningsih, S.ST., M.Biomed di Blahkiuh, Abiansemal, Badung, Bali pada tanggal 1 Januari s.d tanggal 31 Desember 2019 yang yang berjumlah 123 orang. Peneliti menganalisis dengan analisis univariat untuk mengetahui karakteristik responden terdiri dari usia, pendidikan dan pekerjaan, paritas, kadar hemoglobin dan berat bayi lahir.dan bivariat. Analisis bivariat menggunakan uji Chi kuadrat untuk mencari hubungan antara kadar hemoglobin dengan berat bayi lahir.

HASIL

\section{Analisis Univariat}

Tabel 1. Karakteristik Responden

\begin{tabular}{lcc}
\hline Karakteristik & Frekuensi & Persen(\%) \\
\hline Usia (tahun) & & \\
$<20$ & 15 & 12,2 \\
$20-35$ & 97 & 78,9 \\
$>35$ & 11 & 8,9 \\
\hline Total & 123 & 100 \\
\hline Pendidikan & & \\
Dasar & 30 & 24,4 \\
Menengah & 56 & 45,5 \\
Tinggi & 37 & 30,1 \\
\hline Total & 123 & 100 \\
\hline Pekerjaan & & \\
Tidak Bekerja & 45 & 36,6 \\
Bekerja & 78 & 63,4 \\
\hline Total & 123 & 100 \\
\hline
\end{tabular}

Dari tabel 1 dapat diketahui bahwa, dari 123 responden mayoritas ibu hamil memiliki usia 20 - 35 tahun yaitu sebanyak 97 orang (78,9\%). Berdasarkan pendidikan, diketahui dari 123 orang responden, paling banyak yaitu 56 responden $(58,2 \%)$ memiliki pendidikan menengah. Berdasarkan pekerjaan responden, paling banyak yaitu 78 responden $(63,4 \%)$ bekerja.

Tabel 2. Distribusi frekuensi kadarhemoglobin ibu hamil

\begin{tabular}{lcc}
\hline Kadar Hemoglobin & f & \% \\
\hline Tidak anemia & 83 & 67,5 \\
Anemia & 40 & 32,5 \\
\hline Total & $\mathbf{1 2 3}$ & $\mathbf{1 0 0}$ \\
\hline
\end{tabular}

Dari tabel 2 dapat diketahui bahwa mayoritas ibu hamil adalah tidak anemia yaitu 83 responden $(66,7 \%)$. Artinya sebagian besar ibu hamil memiliki kadar hemoglobin $\geq 11 \mathrm{gr} / \mathrm{dl}$.

Tabel 3. Distribusi frekuensi berat bayi lahir

\begin{tabular}{lcc}
\hline Berat Bayi Lahir & f & \% \\
\hline Normal & 92 & 74,8 \\
Rendah & 16 & 13,0 \\
Lebih & 15 & 12,2 \\
\hline Total & $\mathbf{1 2 3}$ & $\mathbf{1 0 0}$ \\
\hline
\end{tabular}

Dari tabel 3 dapat diketahui bahwa mayoritas berat bayi lahir adalah normal yaitu 92 responden 
(74,8\%). Artinya ibu bersalin memiliki bayi dengan berat lahir 2500 - 4000gram.
77 responden $(62,6 \%)$. Berdasarkan pendidikan, dari 56 responden yang berpendidikan menengah, mayoritas ibu memiliki berat bayi lahir normal yaitu 46 responden $(37,4 \%)$.
Tabel 4. Tabulasi Silang karakteristik responden dengan kadar hemoglobin ibu hamil

\begin{tabular}{lcccccc}
\hline & \multicolumn{4}{c}{ Kadar hemoglobin } & \multicolumn{2}{c}{ Total } \\
\cline { 2 - 6 } Karakteristik & \multicolumn{3}{c}{ Tidak anemia } & \multicolumn{2}{c}{ Anemia } & \multicolumn{2}{c}{ Tot } \\
\hline & f & $\mathbf{\%}$ & $\mathbf{f}$ & $\mathbf{\%}$ & $\mathbf{f}$ & $\mathbf{\%}$ \\
\hline Usia (tahun) & & & & & & \\
$<20$ & 6 & 4,9 & 9 & 7,3 & 15 & 12,2 \\
$20-35$ & 73 & 59,3 & 24 & 19,5 & 97 & 78,9 \\
$>35$ & 4 & 3,3 & 7 & 5,7 & 11 & 8,9 \\
\hline Total & $\mathbf{8 3}$ & $\mathbf{6 7 , 5}$ & $\mathbf{4 0}$ & $\mathbf{3 2 , 5}$ & $\mathbf{1 2 3}$ & $\mathbf{1 0 0}$ \\
\hline Pendidikan & & & & & & \\
Dasar & 17 & 13,8 & 13 & 10,6 & 30 & 24,4 \\
Menengah & 44 & 35,8 & 12 & 19,8 & 56 & 45,5 \\
Tinggi & 22 & 17,9 & 15 & 12,2 & 37 & 30,1 \\
\hline Total & $\mathbf{8 3}$ & $\mathbf{6 7 , 5}$ & $\mathbf{4 0}$ & $\mathbf{3 2 , 5}$ & $\mathbf{1 2 3}$ & $\mathbf{1 0 0}$ \\
\hline Pekerjaan & & & & & & \\
Tidak Bekerja & 27 & 22,0 & 18 & 14,6 & 45 & 36,6 \\
Bekerja & 56 & 45,5 & 22 & 17,9 & 78 & 63,4 \\
\hline Total & $\mathbf{8 3}$ & $\mathbf{6 7 , 5}$ & $\mathbf{4 0}$ & $\mathbf{3 2 , 5}$ & $\mathbf{1 2 3}$ & $\mathbf{1 0 0}$ \\
\hline & & & & & & \\
\hline
\end{tabular}

Dari tabel 4 menunjukan tabulasi silang antara karakteristik dengan kadar hemoglobin. Berdasarkan usia, dari 97 responden yang berumur 20 - 35 tahun mayoritas ibu tidak mengalami anemia yaitu 73 responden $(59,3 \%)$. Berdasarkan pendidikan, dari 56 responden yang berpendidikan menengah mayoritas ibu tidak mengalami anemia yaitu 44 responden $(35,8 \%)$. Berdasarkan pekerjaan, dari 78 responden yang bekerja mayoritas ibu tidak mengalami anemia yaitu 56 responden $(45,5 \%)$.

Tabel 5. Tabulasi Silang karakteristik responden berat bayi lahir

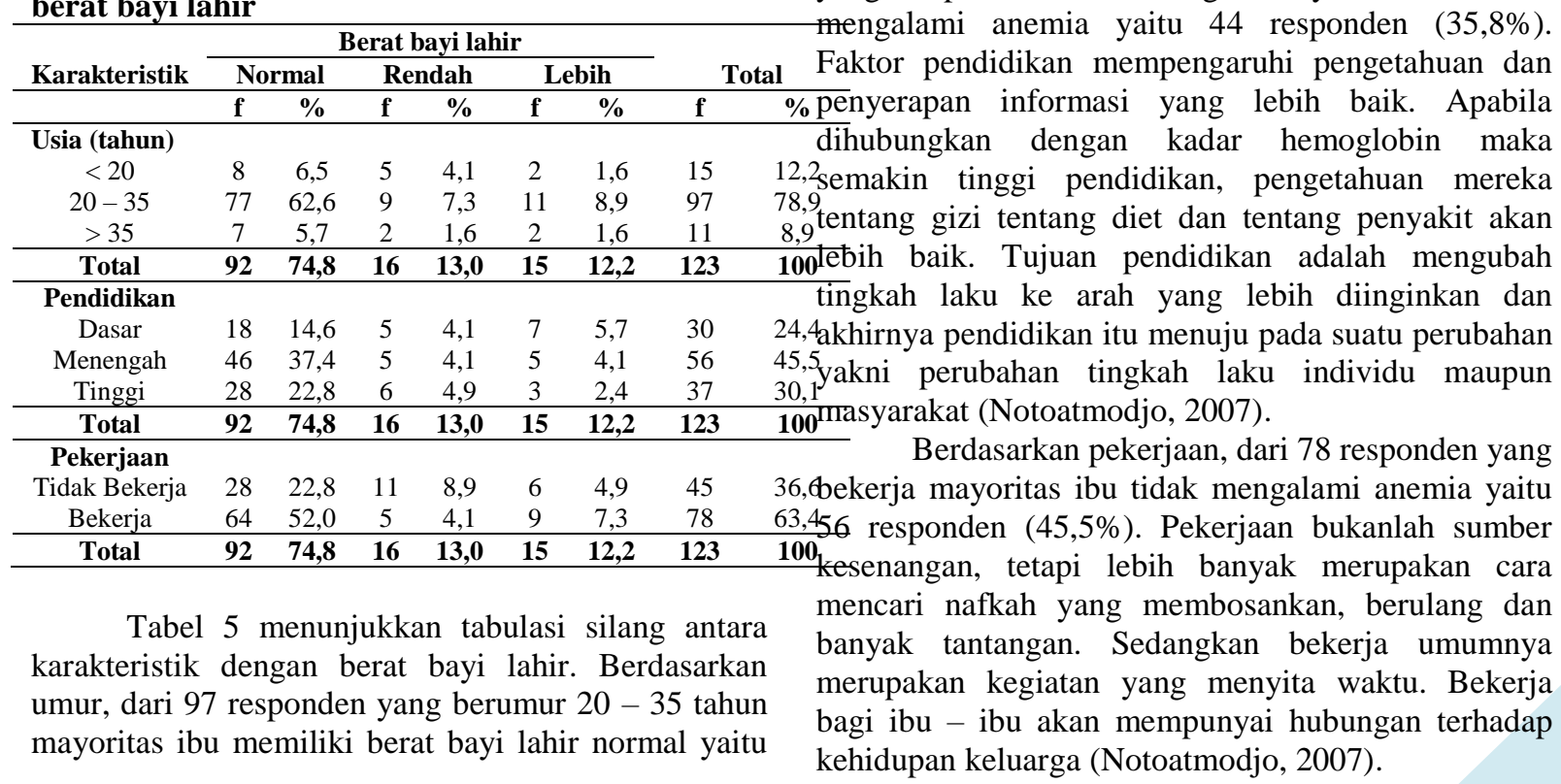

Tabel 6 Hubungan antara kadar hemoglobin dan berat bayi lahir

\begin{tabular}{|c|c|c|c|c|c|c|c|c|c|}
\hline \multirow{3}{*}{$\begin{array}{c}\text { Kadar } \\
\text { Hemoglobin }\end{array}$} & \multicolumn{6}{|c|}{ Berat Bayi Lahir (BBL) } & \multirow{2}{*}{\multicolumn{2}{|c|}{ Total }} & \multirow{3}{*}{$\mathrm{p}$} \\
\hline & \multicolumn{2}{|c|}{ Normal } & \multicolumn{2}{|c|}{ Rendah } & \multicolumn{2}{|c|}{ Lebih } & & & \\
\hline & $\mathrm{f}$ & $\%$ & $\mathrm{f}$ & $\%$ & $\mathrm{f}$ & $\%$ & $\mathrm{f}$ & $\%$ & \\
\hline Tidak & 77 & 62,6 & 4 & 3,3 & 2 & 1,6 & 83 & 67,5 & \\
\hline Anemia & & & & & & & & & 0,000 \\
\hline Anemia & 15 & 12,2 & 12 & 9,8 & 13 & 10,6 & 40 & 32,5 & \\
\hline Total & 91 & 74,0 & 17 & 13,8 & 15 & 12,2 & 123 & 100 & \\
\hline
\end{tabular}

Hasil analisis Chi kuadrat menunjukan bahwa nilai $\mathrm{p}(0,000)<\alpha(0,05)$ berarti $\mathrm{H} 0$ ditolak artinya ada hubungan antara kadar hemoglobin dan berat bayi lahir.

\section{PEMBAHASAN}

Berdasarkan usia, dari 97 responden yang berumur 20 - 35 tahun mayoritas ibu tidak mengalami anemia yaitu 73 responden $(59,3 \%)$. Hal ini berarti usia seseorang mempunyai kecenderungan mempengaruhi kadar hemoglobin. Namun hal ini tentunya tidak hanya disebabkan oleh satu faktor saja, misalnya faktor kehidupan yang lebih baik, aktifitas fisik yang berkurang, makanan yang semakin baik serta hal-hal lain yang tidak diamati dalam penelitian. Faktor resiko tinggi untuk teradi anemia selama kehamilan adalah hamil dua kehamilan yang berdekatan, paritas, sering mual dan muntah, tidak mengkonsumsi cukup zat besi, hamil saat remaja, dan kehilangan banyak darah (Proverawati, 2011).

Berdasarkan pendidikan, dari 56 responden yang berpendidikan menengah mayoritas ibu tidak mengalami anemia yaitu 44 responden (35,8\%). Faktor pendidikan mempengaruhi pengetahuan dan dihubungkan dengan kadar hemoglobin maka semakin tinggi pendidikan, pengetahuan mereka , tentang gizi tentang diet dan tentang penyakit akan lebih baik. Tujuan pendidikan adalah mengubah 4,4akhirnya pendidikan itu menuju pada suatu perubahan 45,5yakni perubahan tingkah laku individu maupun rakat (Notoatmodjo, 2007)

kehidupan keluarga (Notoatmodjo, 2007). 
Berdasarkan umur, dari 97 responden yang berumur 20 - 35 tahun mayoritas ibu memiliki berat bayi lahir normal yaitu 77 responden $(62,6 \%)$. Hal ini berarti usia seseorang mempunyai kecenderungan mempengaruhi berat bayi lahir normal. Usia reproduksi yang optimal bagi seorang ibu adalah 2035 tahun. Pada usia tersebut Rahim sudah siap untuk menerima kehamilan, mental sudah matang dan mampu merawat bayinya. Pada usia kurang dari 20 tahun organ reproduksi belum berfungsi sempurna, Rahim dan panggul ibu belum mencapai ukuran dewasa sehingga bila terjadi kehamilan lebih mudah mengalami komplikasi dan pada usia lebih dari 35 tahun menjadi penurunan kesehatan reproduksi karena proses degeneratif sudah muncul salah satu efek dari proses degeneratif adalah sclerosis pembuluh darah arteri kecil dan arteriole myometrium menyebabkan aliran darah ke myometrium tidak merata dan maksimal sehingga dapat mempengaruhi penyaluran nutrisi ibu ke janin dan membuat gangguan pertumbuhan janin di rahim (Prawirohardjo, 2008).

Berdasarkan pendidikan, dari 56 responden yang berpendidikan menengah, mayoritas ibu memiliki berat bayi lahir normal yaitu 46 responden $(37,4 \%)$. pengetahuan dan penyerapan informasi yang lebih baik. Apabila dihubungkan dengan berat bayi lahir maka semakin tinggi pendidikan, pengetahuan mereka tentang gizi tentang diet dan tentang penyakit akan lebih baik.

Hasil analisis Chi kuadrat menunjukan bahwa nilai $\mathrm{p}(0,000)<\alpha(0,05)$ berarti H0 ditolak artinya ada hubungan antara kadar hemoglobin dan berat bayi lahir.

Secara teoritis kadar hemoglobin ibu hamil sangat mempengaruhi berat bayi yang dilahirkan. Kadar hemoglobin tidak normal pada ibu hamil akan menambah resiko BBLR, gangguan perkembangan otak, resiko perdarahan sebelum dan saat persalinan, bahkan dapat menyebabkan kematian pada ibu dan bayinya, jika ibu mengalami anemia berat. Keadaan ini karena kurangnya suplai darah nutrisi akan oksigen pada plasenta yang akan berpengaruh pada fungsi plasenta terhadap janin (Departemen Kesehatan RI, 2012).

Hasil penelitian ini sesuai dengan hasil penelitian yang dilakukan (Sekhavat, Davar and Hosseinidezoki, 2011) yang menyatakan Anemia ibu berhubungan dengan pengaruh berat badan lahir. Hasil penelitian ini sesuai dengan penelitian (Zein, 2006) yang menyatakan ada korelasi yang signifikan antara kadar hemoglobin dan berat bayi lahir. Penelitian (Simanjuntak, 2008) menyatakan bahwa ada hubungan kejadian anemia dengan berat bayi lahir rendah. Pemberian suplemen besi setiap hari pada ibu hamil sampai minggu ke-28 kehamilan pada ibu hamil yang belum mendapat besi dan nonanemik ( $\mathrm{Hb}<11$ $\mathrm{g} / \mathrm{dl}$ dan ferritin $<20 \mathrm{mg} / \mathrm{l}$ ) menurunkan prevalensi anemia dan bayi berat lahir rendah (Prawirohardjo, 2016).
Kadar $\mathrm{Hb}$ ibu berkorelasi positif dengan berat badan lahir, berat badan lahir bayi yang lahir dari ibu anemia lebih rendah dibandingkan dengan ibu yang tidak anemia. Usia ibu-dewasa muda dikaitkan dengan BBLR. Lebih banyak perhatian nutrisi dan perawatan antenatal dapat mencegah BBLR (Eissa $e t$ al., 2017).

Hasil penelitian dilakukan dengan menganalisis korelasi antara kadar hemoglobin dengan tiga faktor, termasuk menangis spontan untuk menilai Skor APGAR, kelahiran prematur, dan berat badan lahir rendah. Diantara faktor-faktor tersebut, hanya berat badan lahir rendah memiliki tampilan yang signifikan dengan kadar hemoglobin selama kehamilan (Safithri, Kania and Diana, 2019).

\section{KESIMPULAN}

Hasil analisis Chi kuadrat menunjukan bahwa nilai $\mathrm{p}(0,000)<\alpha(0,05)$ berarti $\mathrm{H} 0$ ditolak artinya ada hubungan antara kadar hemoglobin dan berat bayi lahir.

Kadar hemoglobin ibu hamil sangat mempengaruhi berat bayi yang dilahirkan. Kadar hemoglobin tidak normal pada ibu hamil akan menambah resiko BBLR, gangguan perkembangan otak, resiko perdarahan sebelum dan saat persalinan, bahkan dapat menyebabkan kematian pada ibu dan bayinya, jika ibu mengalami anemia berat. Keadaan ini karena kurangnya suplai darah nutrisi akan oksigen pada plasenta yang akan berpengaruh pada fungsi plasenta terhadap janin.

\section{DAFTAR PUSTAKA}

1. Departemen Kesehatan RI (2012) Profil Kesehatan Indonesia 2009.

2. Dinas Kesehatan Provinsi Bali (2017) Profil Kesehatan Provinsi Bali.

3. Eissa, F. et al. (2017) 'The Correlation between Maternal Hemoglobin level and neonatal birth weight', International Journal of Multidisciplinary and Current Research, 5(July), pp. 506-509.

4. Kementrian Kesehatan RI (2017) Survei Demografi dan Kesehatan Indonesia.

5. Mochtar, R. (2012) Sinopsis Obstetri. Jakarta: EGC.

6. Notoatmodjo, S. (2007) Metodologo Penelitian Kesehatan. Jakarta: Rineka Cipta.

7. Nursalam (2007) Konsep dan penerapan metodelogi penelitian ilmu keperawatan; pedoman skripsi, tesis dan instrument penelitian kepperawatan. Jakarta: Salemba.

8. Prawirohardjo, S. (2008) Ilmu Kebidanan. Jakarta: P.T. Bina Pustaka. 
9. Prawirohardjo, S. (2016) Ilmu Kebidanan. 5th edn. Jakarta: Bina Pustaka.

10. Proverawati, A. (2011) Anemia dan Anemia Kehamilan. Yogyakarta: Nuha Medika.

11. Safithri, S. F., Kania, N. and Diana, A. (2019) 'Correlation between Maternal Hemoglobin Level and Birth Weight', Althea Medical Journal, 6(2), pp. 91-94. doi: 10.15850/amj.v6n2.1637.

12. Sekhavat, L., Davar, R. and Hosseinidezoki, S. (2011) 'Relationship between maternal hemoglobin concentration and neonatal birth weight', Hematology, 16(6), pp. 373-376. doi: $10.1179 / 102453311$ X13085644680186.

13. Simanjuntak, N. A. (2008) 'Hubungan Anemia Pada Ibu Hamil dengan Kejadian Bayi Berat Lahir Rendah (BBLR) di Badan Pengelola Rumah Sakit Umum ( BPRSU) Rantauprapat Kabupaten Labuhan Batu.', volume 4.

14. Zein, A. Y. (2006) Hubungan Antara Kadar HB selama kehamilan dan Paritas dengan Berat Bayi Lahir Di Puskesmas Mergangsan Kota Yogyakarta. Skripsi Poltekes Surakarta. 